\title{
MEASUREMENT OF DEGREE OF SATURATION ON MODEL GROUND BY DIGITAL IMAGE PROCESSING
}

\author{
Norimasa Yoshimotoi), Rolando P. ORense ${ }^{\text {ii) }}$, Fumiaki TANABE ${ }^{\text {iii)}}$, \\ NaOtaka KikKawa ${ }^{\text {iv)}, \text { Masayuki Hyodo }}{ }^{\text {v) }}$ and Yukio NaKata ${ }^{\text {vi) }}$
}

\begin{abstract}
The degree of saturation of ground is conventionally measured at discrete points using transducers, soil moisture sensors, etc. In this paper, a novel method was developed to directly measure the degree of saturation of continuous region of ground by noting the variation in color of the ground as the amount of moisture in the soil changes. In this research, a series of experiments was conducted for the purpose of developing a method to measure the degree of saturation of ground by digital image processing. From photo images taken at various soil moisture contents, the colors of the images were converted into numerical values which were then related to known degrees of saturation. The results of the experiments showed that a method to measure the degree of saturation of ground by image processing was possible. The relation between degree of saturation and luminance value can be expressed in terms of second degree function. Good results were obtained for two soil samples with different colors and grain size distributions. The margin of error was in the order of $\pm 5 \%$. The method was validated through vertical seepage tests, where good agreements were obtained between the measured degrees of saturation by tensiometers and those estimated from the proposed method. The method illustrates the possibility of measuring the degree of saturation of a larger portion of the ground, which is difficult to perform using conventional procedures. With this method, contour diagrams of degree of saturation can be produced, making it possible to visualize the propagation of the saturated region.
\end{abstract}

Key words: degree of saturation, image processing, grain color, grain size, model test, seepage (IGC: D4/E7)

\section{INTRODUCTION}

The amount of water in soil, often expressed in terms of the degree of saturation, $S_{\mathrm{r}}$, plays an important role in defining many soil properties, such as strength and permeability. Conventionally, $S_{\mathrm{r}}$ is determined in the laboratory by taking small amounts of soil samples and comparing their weights before and after drying (e.g., Luthin and Miller, 1953; Bruce and Klute, 1956). Although this direct method is inexpensive and easy to implement, it is destructive, time-consuming and does not allow for making repetitions at the same location.

Alternatively, many direct methods are available, such those that make use of electrical resistivity (Umeda, 1969), neutron moderation (Falleiros et al., 1993), gamma ray densitometry (Gurr, 1962) and dielectric capacitance (Uno, 1970; Topp et al., 1990). Some of the dielectric-based methods which use empirically calibrated relationships between volumetric water content and sensor output signal include time domain reflectometry (Nissen et al., 1998), amplitude domain reflectometry
(Nakajima et al., 1998) and frequency domain reflectometry (Lukangu et al., 1999). Indirectly, the degree of saturation can be estimated from soil water characteristic curve based on measured matric suction of the soil, which in turn can be obtained using tensiometers, high air entry ceramic disk, etc. (Fredlund and Rahardjo, 1993).

A major drawback of these methods is that only the $S_{\mathrm{r}}$ at discrete points are measured, and hence do not give an indication of the amount of water in a large region of the ground. Of course, more sensors placed at shorter intervals can be installed in the ground to give a better idea of the distribution of soil moisture in the entire ground; however, the cost involved may be prohibitive for practical purposes. Moreover, the presence of sensors installed in the ground may influence the measurement of $S_{\mathrm{r}}$.

Recent developments in digital technology have led to the development of various image analyzing techniques to examine diverse engineering problems. In hydrology and water resources, for example, image analysis methods have been valuable tools in tracing the movement of immiscible contaminants, such as oil and other

Assistant Professor, Graduate School of Science and Engineering, Yamaguchi University, Yamaguchi, Japan (nyoshi@yamaguchi-u.ac.jp).

Senior Lecturer, Department of Civil and Environmental Engineering, University of Auckland, New Zealand.

ii) Shinko Industries Co. Ltd., Yamaguchi, Japan.

iv) Researcher, Construction Safety Research Group, National Institute of Occupational Safety and Health, Tokyo, Japan.

Professor, Graduate School of Science and Engineering, Yamaguchi University, Yamaguchi, Japan.

vi) ditto.

The manuscript for this paper was received for review on April 1, 2009; approved on August 30, 2010.

Written discussions on this paper should be submitted before September 1, 2011 to the Japanese Geotechnical Society, 4-38-2, Sengoku, Bunkyo-ku, Tokyo 112-0011, Japan. Upon request the closing date may be extended one month. 
non-aquaeous phase liquids (NAPL), in unsaturated heterogeneous porous media. For instance, Schincariol and Schwartz (1990) performed physical model studies to investigate the unstable behavior of aqueous phase plumes with densities larger than the ambient water by analysing photographs of the transport and flow phenomena. Darnault et al. (1998) developed a method where the intensity of transmitted light through a thin two-dimensional flume was recorded and water saturation (in two-phase NAPL-water experiments) was correlated to the average hue (color) value of the pixels. Kechavarzi et al. (2000) developed a technique to determine the saturation distribution of NAPL, water and air using a digital infrared camera and the saturation profiles were determined based on the measurement of the optical density defined for the reflected luminous intensity of the sample.

Image analyses have also been used in geotechnical engineering to investigate ground deformation and soil movement velocities with high accuracy. Particle image velocimetry (PIV), which was originally developed for fluid mechanics applications (Visualization Society of Japan, 2002), has been applied to the measurement of the local velocities within soil masses (White et al., 2003). This visualisation method makes use of digital image processing technology to obtain information on the distribution of the luminance value of the digital image taken to quantify alterations in time and space with high reliability. Digital image processing has been used recently, for example, in examining the quality rating of stones and to categorize the degree of weathering of granite through the color and tone of the stones (Urano et al., 2006).

In this research, an innovative method of measuring the degree of saturation of ground is proposed based on the variation in the color of the ground as the soil moisture changes. By taking photos of the ground using digital cameras and converting the colors of the photo images obtained into numerical values which can be associated to known degrees of saturation, $S_{\mathrm{r}}$ of the whole ground can be determined more easily. To validate the method, experiments were performed on model grounds under drained and undrained conditions and the results obtained showed good agreement with the values obtained using the conventional method.

\section{DEVELOPMENT OF METHOD}

\section{Samples Used}

In this research, experiments were conducted using two types of soils: Toyoura sand and Tottori silt. The light brown-colored Toyoura sand was selected because it is popularly used in various studies related to the mechanics of soils. On the other hand, to provide a stark contrast to Toyoura sand, the gray-colored Tottori silt was chosen because it has smaller particle size than Toyoura sand and therefore has lower permeability. Note that in this research, the measurement of $S_{\mathrm{r}}$ is based on the color of soil images and therefore, the applicability of the method has to be examined considering a wide range of soil samples. The grain size distribution curves of the soils are shown in Fig. 1 while the index properties are listed in Table 1.

\section{Experimental Method \\ Equipment}

In order to develop a method to measure the degree of saturation of ground, different factors need to be examined and therefore, soil specimens that can be prepared quite easily were preferred. For this purpose, an acryltype container, $5 \mathrm{~cm}$ high and $2.1 \mathrm{~cm}$ in diameter was employed (see Fig. 2(a)). Moreover, in order to maintain the amount of light constant, the locations of the three desk lamps used were adjusted and curtains were employed to shade the work site from unnecessary lights which may affect the images taken. An ordinary digital camera commonly available in the market was used for taking digital photos. In this research, the following settings were adopted: shutter speed, $T_{\mathrm{v}}=1 / 20 \mathrm{sec}$; aperture value, $A_{\mathrm{v}}$ $=4.5$; image resolution $=0.05 \mathrm{~mm} /$ pixel; and camera effective pixels $=2592 \times 1944$ pixels.

\section{Experimental Procedure}

A Soil sample was placed inside the acryl container with its water content adjusted to a prescribed degree of saturation and compacted to attain a relative density, $D_{\mathrm{r}}$

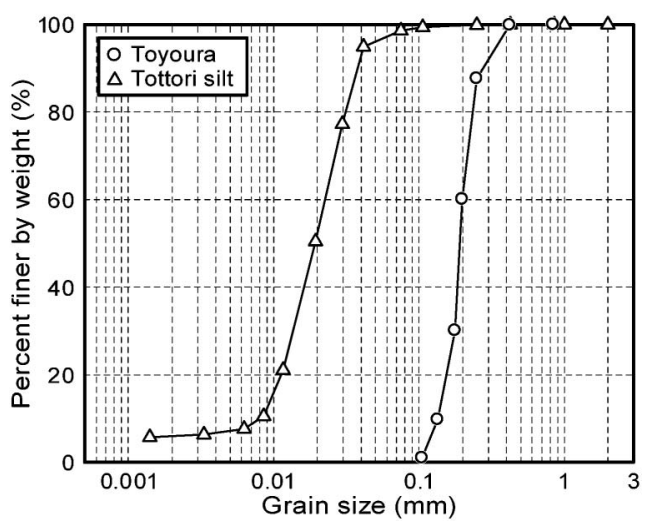

Fig. 1. Grain size distribution curves of the soils used

Table 1. Index properties of the soils used

\begin{tabular}{c|c|c|c|c|c|c}
\hline Sample & $\begin{array}{c}\rho_{\mathrm{s}} \\
\left(\mathrm{g} / \mathrm{cm}^{3}\right)\end{array}$ & $e_{\max }$ & $e_{\min }$ & $\begin{array}{c}D_{50} \\
(\mathrm{~mm})\end{array}$ & $\begin{array}{c}\rho_{\mathrm{d}} \text { at test } \\
\left(\mathrm{g} / \mathrm{cm}^{3}\right)\end{array}$ & $e$ at test \\
\hline Toyoura sand & 2.643 & 0.973 & 0.635 & 0.200 & 1.550 & 0.705 \\
\hline Tottori silt & 2.665 & 2.127 & 1.118 & 0.019 & 1.149 & 1.320 \\
\hline
\end{tabular}




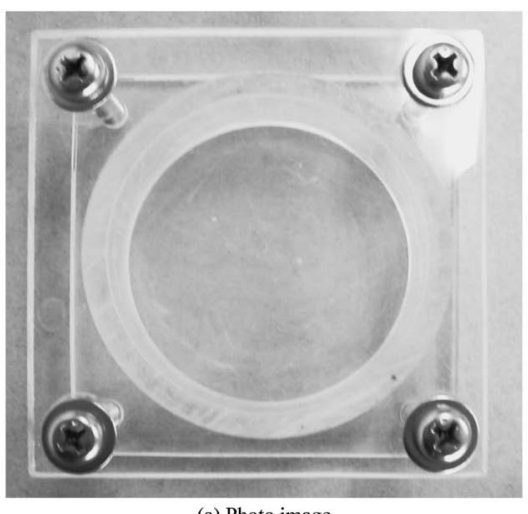

(a) Photo image

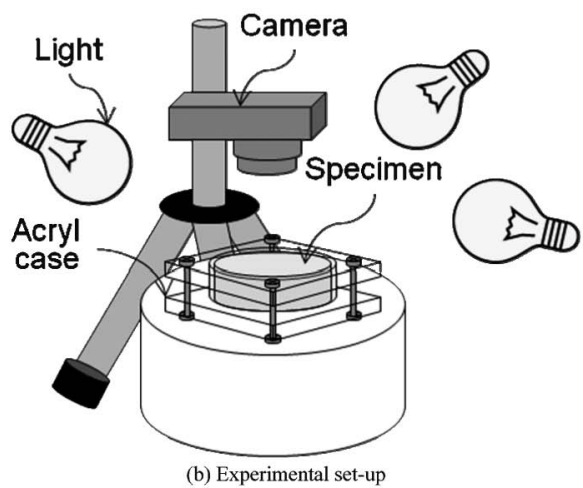

Fig. 2. Acryl type container: (a) photo image, and (b) experimental set-up

$=80 \%$. The container with the sample in it was sealed, set on the photo stand, and photos of the upper surface were taken from the top using a digital camera fixed in position (see Fig. 2(b)). In this research, careful attention was placed on the change in color of the specimen as the amount of water in the sample was varied, and such a change in color was converted into digital value which could indicate the $S_{\mathrm{r}}$ of the soil. Note that each pixel of the digital image has RGB scale values, which are the red, green and blue scale values, and the color in each pixel is expressed as a mixture of the RGB colours in each pixel, which can range from 0 to 255 . In this study, the average of red, green and blue scale values in each pixel was used to represent the intensity of color, referred to as the luminance value, in each pixel. A high luminance value indicates that the image is bright while a low value refers to a dark image.

Note that the luminance value is greatly influenced by the quantity of light available when the photo image is taken. For this purpose, the experiments were conducted in a dark room, which was covered with the sun-block curtains so that lights from other sources were negligible. The only source of light was the desk lamps whose positions were adjusted so that they focused in three directions and light scattering was negligible. To maintain constant condition, the positions of the desk lamps and the stands, as well as the position of the camera were all fixed. Thus, for a given series of tests, the only condition that changed was that of the sample, i.e., only the sam-

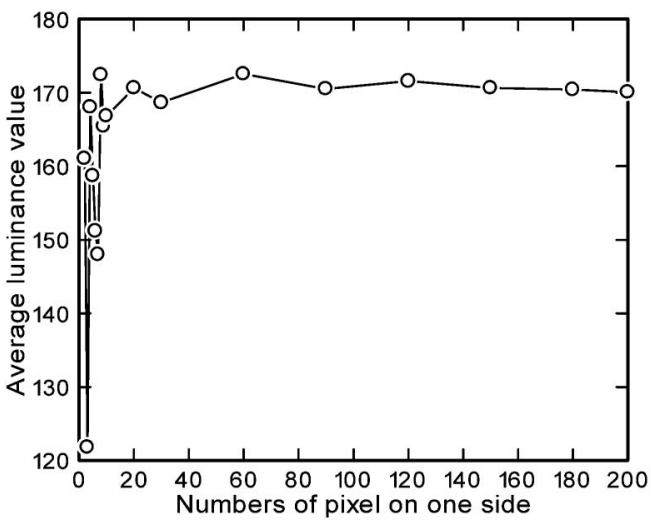

Fig. 3. Relation between luminance value and number of pixels

ples were replaced. In the experiments, three saturation levels were investigated, with $S_{\mathrm{r}}=0 \%, 30 \%$, and $60 \%$ and the relation between each $S_{\mathrm{r}}$ and the corresponding luminance value was examined. To see more clearly the change in saturation level based on the variation in color of the sample, a bright red food coloring agent was mixed with water used. For consistency, the distance between the test specimen and the camera lens was set to $120 \mathrm{~mm}$.

\section{Evaluation of Luminance Value}

In this research, $S_{\mathrm{r}}$ is evaluated from the luminance value of a particular image taken. However, the color intensity of a particular photo image of soil particles is dependent on the size/area of the image itself. This is because soil particles, which are of finite size, have their own respective colors which could affect the luminance value of the area under consideration. This is especially true in the case of small images whose sizes are of the same order as the size of the soil grains being examined. To minimize the effect of the color of each individual soil particle, the luminance value within the area is averaged. Obviously, as the size of the image being examined increases, the scattering of the luminance value decreases and the average value tends to approach a unique one.

In order to evaluate the optimum size of the image to be analyzed, the photo images taken were cut into several areas, each consisting of an arbitrary number of pixels, and the average luminance value of each area was examined. A typical result for Toyoura sand is shown in Fig. 3. It is observed that the scattering of the luminance value greatly decreases when the area considered exceeded 50 pixels, and the average value became constant when the area has more than 150 pixels. From the above results, an image measuring $200 \times 200$ pixels would provide a stable value, and since this corresponds to an image measuring about $1 \mathrm{~cm} \times 1 \mathrm{~cm}$ in size, this range was adopted in this research. Note that since Tottori silt has smaller-sized grains than Toyoura sand, the said image size would give good results as well.

\section{Experimental Results}

The method of analyzing images from the photo taken is discussed next. A photo image was taken for each sam- 
ple with the specified degree of saturation. An example of one of the photos is shown in Fig. 4 (Toyoura sand $S_{\mathrm{r}}=$ $0 \%$ ). From each photo, five images, each measuring 200 $\times 200$ pixels, were taken at different locations, and the variations of the average luminance from these five images were examined.

The images taken for samples of Toyoura sand under different degrees of saturation are shown in Figs. 5(a)-(c) while the corresponding luminance values for each image are listed in Table 2. On the other hand, the images for Tottori silt are shown in Figs. 6(a)-(c) while the corresponding luminance values are given in Table 3 . The locations of the images as indicated in the tables correspond

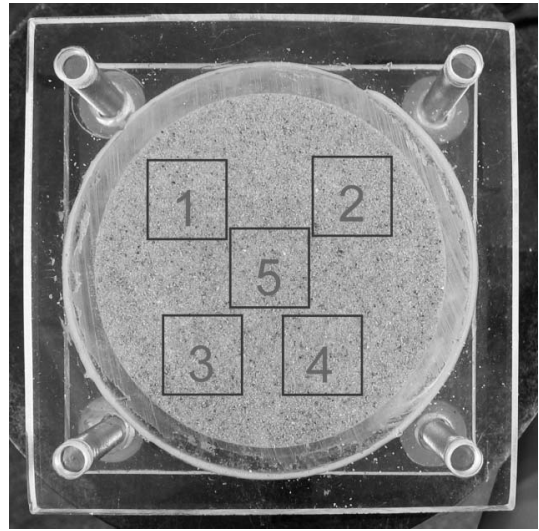

Fig. 4. Example of photo image taken (Toyoura sand, $S_{\mathrm{r}}=0 \%$ ) to those shown in Fig. 4. Note that the "average" value of the five images listed in the table represents the mean of luminance values of the said sample, while the "deviation" refers to the variation with respect to the average value. It can be seen from the tables that for both Toyoura sand and Tottori silt, the deviations corresponding to the image taken from the top of the acryl case are very small, indicating that it is possible to obtain good steady images. Moreover, it can be observed from the figures

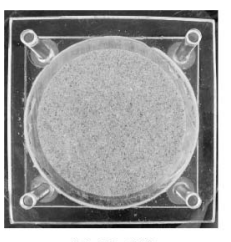

(a) $S_{\mathrm{r}}=0 \%$

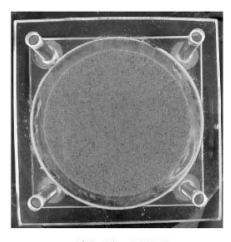

(b) $S_{\mathrm{r}}=30 \%$

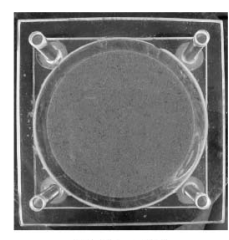

(c) $S_{\mathrm{r}}=60 \%$
Fig. 5. Photo images of Toyoura sand at various degrees of saturation

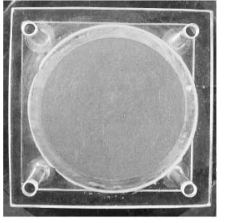

(a) $S_{\mathrm{r}}=0 \%$

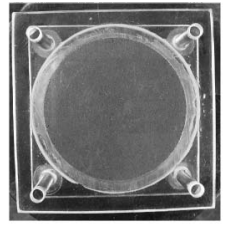

(b) $S_{\mathrm{r}}=30 \%$

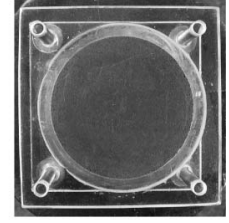

(c) $S_{\mathrm{r}}=60 \%$
Fig. 6. Photo images of Tottori silt at various degrees of saturation

Table 2. Luminance values for each degree of saturation of Toyoura sand

\begin{tabular}{c|c|c|c|c|c|c|c|c}
\hline \multicolumn{3}{c|}{$S_{\mathrm{r}}=\%$} & \multicolumn{3}{c}{$S_{\mathrm{r}}=30 \%$} & \multicolumn{3}{c}{$S_{\mathrm{r}}=60 \%$} \\
\hline Location & $\begin{array}{c}\text { Luminance } \\
\text { value }\end{array}$ & Deviation & Location & $\begin{array}{c}\text { Luminance } \\
\text { value }\end{array}$ & Deviation & Location & $\begin{array}{c}\text { Luminance } \\
\text { value }\end{array}$ & Deviation \\
\hline 1 & 155.02 & 0.43 & 1 & 120.96 & 0.33 & 1 & 105.47 & 0.29 \\
\hline 2 & 154.77 & 0.18 & 2 & 121.73 & 0.44 & 2 & 105.43 & 0.25 \\
\hline 3 & 154.85 & 0.26 & 3 & 121.13 & 0.16 & 3 & 104.45 & 0.73 \\
\hline 4 & 153.96 & 0.63 & 4 & 122.18 & 0.89 & 4 & 105.23 & 0.05 \\
\hline 5 & 154.33 & 0.26 & 5 & 120.44 & 0.85 & 5 & 105.32 & 0.14 \\
\hline Average & 154.59 & & Average & 121.29 & & Average & 105.18 & \\
\hline
\end{tabular}

Table 3. Luminance values for each degree of saturation of Tottori silt

\begin{tabular}{c|c|c|c|c|c|c|c|c}
\hline \multicolumn{3}{c|}{$S_{\mathrm{r}}=0 \%$} & \multicolumn{3}{c|}{$S_{\mathrm{r}}=30 \%$} & \multicolumn{3}{c}{$S_{\mathrm{r}}=60 \%$} \\
\hline Location & $\begin{array}{c}\text { Luminance } \\
\text { value }\end{array}$ & Deviation & Location & $\begin{array}{c}\text { Luminance } \\
\text { value }\end{array}$ & Deviation & Location & $\begin{array}{c}\text { Luminance } \\
\text { value }\end{array}$ & Deviation \\
\hline 1 & 155.80 & 0.93 & 1 & 117.74 & 0.89 & 1 & 100.80 & 1.24 \\
\hline 2 & 154.31 & 0.56 & 2 & 118.06 & 1.21 & 2 & 100.04 & 0.48 \\
\hline 3 & 154.16 & 0.71 & 3 & 116.65 & 0.20 & 3 & 98.45 & 1.11 \\
\hline 4 & 154.99 & 0.12 & 4 & 115.75 & 1.10 & 4 & 99.65 & 0.09 \\
\hline 5 & 155.07 & 0.20 & 5 & 116.04 & 0.81 & 5 & 98.87 & 0.69 \\
\hline Average & 154.87 & & Average & 116.85 & & Average & 99.56 & \\
\hline
\end{tabular}




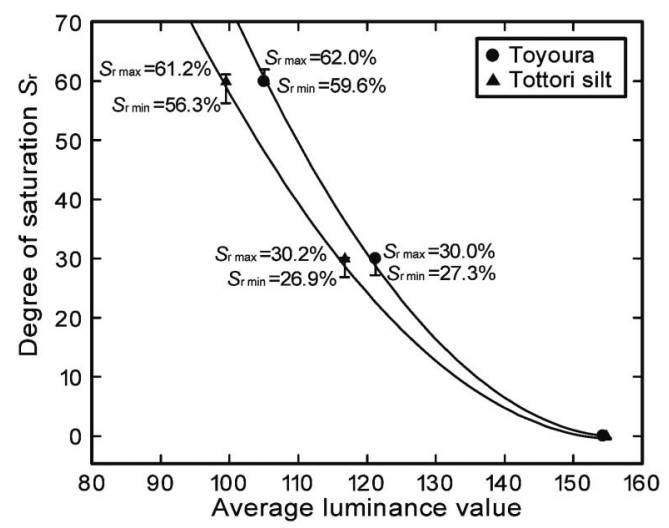

Fig. 7. Relation between luminance value and degree of saturation

and tables that as the amount of water increased, soil moisture increased and the color became darker; consequently, the luminance value decreased. Note however that because of its blackish color, the luminance values corresponding to Tottori silt are much smaller than those for Toyoura sand.

It is worthy to mention that in this research, new soil specimens were prepared for each case. Moreover, the degree of saturation was calculated from the moisture content and relative density of the sample during the specimen preparation. The relations between the degree of saturation and luminance value for Toyoura sand and Tottori silt obtained from the experiment are plotted as shown in Fig. 7. It can be seen that for both soils, the data points can be approximated by a second-order curve which can be expressed as follows:

$$
S_{\mathrm{r}}=a \times R G B^{2}-b \times R G B+c
$$

where $S_{\mathrm{r}}$ is the degree of saturation (\%) and $R G B$ is the luminance value. For Toyoura sand, the values of constants are as follows: $a=0.0223, b=7.0121, c=551.10$. On the other hand, for Tottori silt, the values of the constants are $a=0.0178, b=5.6021, c=440.17$. It can be seen from the curves that at high saturation levels, the degree of saturation is very sensitive to the luminance value. Note that although a higher order curve may also be used, the limited data presented herein showed that a second-order curve is sufficient to represent the relationship obtained.

The accuracy of the experiments was examined using the above-mentioned approximate curve equation. The minimum and maximum luminance values for each sample were considered and the corresponding $S_{\mathrm{r}}$ was estimated using the appropriate approximate curve equation. The results, depicted in Fig. 7, showed that for both Toyoura sand and Tottori silt, the accuracy of the estimate is generally good, with an error margin for $S_{\mathrm{r}}$ at about $\pm 5 \%$. Although luminance values for higher $S_{\mathrm{r}}$ (say $>60 \%$ ) can be obtained by extrapolation, it can be noticed that the curve becomes steeper, indicating possibly higher error margin. As will be shown later, the margin of error is about $\pm 10 \%$ for $S_{\mathrm{r}}=100 \%$.

Based on the examination presented, it was confirmed that the degree of saturation of the sample can be determined based on the change in color that accompanied the change in the amount of moisture within the sample. It is worthy to mention that similar results were obtained for both Toyoura sand and Tottori silt, notwithstanding the fact that the latter has smaller particle size and blackish color. Thus, it can be said that the degree of saturation of an unsaturated ground can be measured through the proposed method within a reasonable level of accuracy.

It should be borne in mind though that, as the experiments revealed, the luminance value can be easily affected by the lighting available. Therefore, specific conditions, such as the brightness level of the desk lamps and the distance of the camera from the sample being constant for all cases, must be always satisfied. In the experiments, the positions of the light stand, the camera, and the sample stand were always fixed, and only the $S_{\mathrm{r}}$ of the specimen placed on the sample stand was changed.

\section{VALIDATION TESTS}

In order to verify the applicability of the proposed method to measure the degree of saturation by digital image processing, and to examine the unsaturated seepage characteristics of Toyoura sand and Tottori silt, vertical seepage tests were performed. The seepage apparatus was constructed based on the test results that the degree of saturation can be determined from the luminance value of the photo image of the sample. Moreover, to verify whether the saturation levels obtained during the infiltration are accurate, tensiometers were attached through the side of the apparatus and the monitored readings were compared to those obtained using the proposed method.

\section{Methodology \\ Apparatus}

The experimental set-up for the validation test is shown on Fig. 8. In the figure, Containers I and II can be changed easily without any disturbances of cameras and lights. Therefore, after calibration tests in Container II, we can shift to seepage tests in Container I.

Container I for the vertical seepage test was $100 \mathrm{~mm}$ wide $\times 700 \mathrm{~mm}$ high $\times 50 \mathrm{~mm}$ deep. It was made up of acryl boards in front and at the back while aluminum channels were used at the sides. Thus, photo images can be taken from the front as water with dissolved food coloring agent was infiltrated from the top of the container to the bottom.

From the results of previous tests, the importance of the camera, light, and sample position to be always fixed in order to obtain steady image information has been emphasized. In order to fix the position of the camera and the lamps, ladder-like stands were provided for fixing each one of them at the same positions. The structure shown on the left side of Fig. 8 is the stand for the camera; all in all, six cameras can be set in this stand. It is possible to take photo images of the entire sample by taking photos simultaneously with all cameras and from the images obtained, the distribution of degrees of saturation 


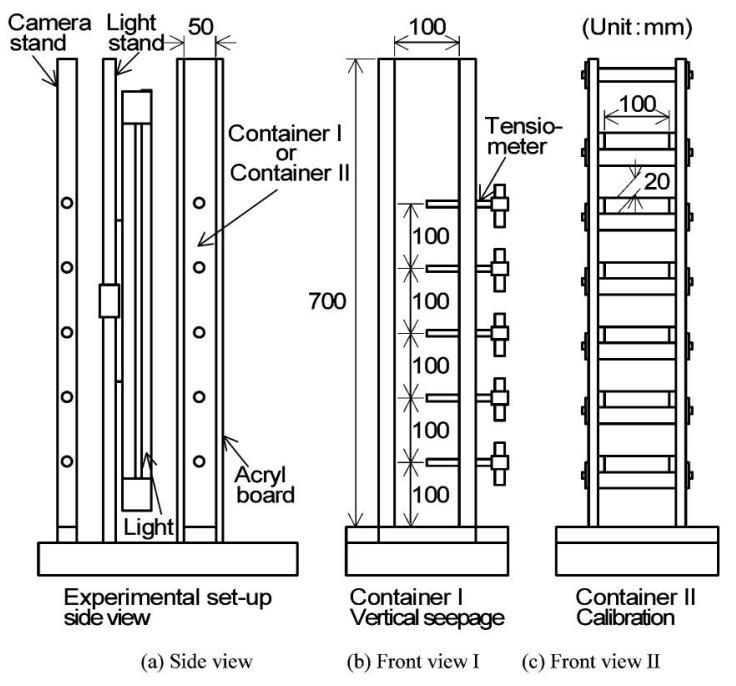

Fig. 8. Diagram of the apparatus used for vertical seepage tests

within the entire ground can be obtained. The light stand shown in the figure is for fixing the lamps between the sample container and the camera. Each of these structures can be fixed to the base frame using screws.

Under the sample container, a drain pipe (for air and water) fitted with a check valve was installed, making it possible to perform seepage tests with air-drained and water-drained bottom conditions (hereinafter referred to as "drained condition"), as well as air-undrained and water-undrained bottom conditions (hereinafter called as "undrained condition"). Tensiometers can be installed at four points on the side of the container, and these are numbered in sequence, starting from $100 \mathrm{~mm}$ from the base frame and going up with a spacing of $100 \mathrm{~mm}$. The tensiometer has a diameter of $5.9 \mathrm{~mm}$ and $86 \mathrm{~mm}$ long, and when used in the vertical seepage test apparatus, it can measure the matric potential at the center of the container. From the known soil water characteristic curves of Toyoura sand and Tottori silt, the corresponding degree of saturation can be estimated. The tensiometer used has an air entry value, $\mathrm{AEV}=50 \mathrm{kPa}$. From previous tests, this type of tensiometer has been proven to have good water penetration with minimal time lag (JGS, 2004).

Phase 1: Calibration Test

In the method developed above to measure the saturation level, it is necessary to obtain the relation between the degree of saturation and luminance value of the sample beforehand, and to formulate the appropriate seconddegree approximate function. Moreover, it is necessary that the position of the camera, lamp, and sample be made the same throughout the whole time the said relation was being obtained.

The calibration containers (Container II in Fig. 8), where the samples with the prescribed water content were placed, were positioned in the same way as the soil container used in the seepage experiment (Container I). The dimensions of the container were $100 \mathrm{~mm}$ wide, $20 \mathrm{~mm}$ high and $20 \mathrm{~mm}$ deep. The general view of one calibration container is shown in Fig. 9. With this size, it was

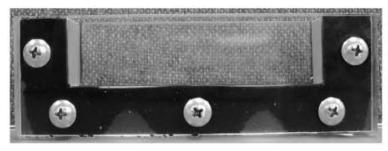

(a) Front view

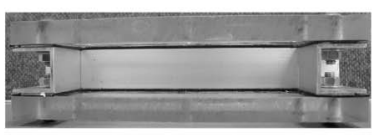

(b) Top view
Fig. 9. Container used during calibration phase: (a) front view, and (b) top view

possible to prepare a sample with saturation level as uniform as possible. Samples were prepared in each calibration container at the prescribed water content after which each container with the prepared soil specimen was then fixed into Container II, as shown in Fig. 8. Then, the relation between the degree of saturation and the luminance value was obtained for each camera position (as used in the seepage test) in the same manner as outlined earlier. Note that as in the preliminary tests, Toyoura sand and Tottori silt were used in the vertical seepage tests; hence, calibration was conducted for these two soil types.

It is worth mentioning that the calibration is necessary prior to the actual tests in order to account for possible minor changes in camera location, lighting, etc. In other words, the colors have to be "calibrated" prior to each test and therefore, there is no need for the use of any color reference scale.

Phase 2: Seepage Test

Next, while maintaining the same conditions as adopted during calibration, the samples were prepared in the seepage soil container, and after the apparatus has been set-up, the experiment was started. The procedure in conducting the seepage experiment is as follows.

First, the positions of the camera and lamps were fixed. The camera positions were referred to based on their location from the bottom (No. 1, No. 2, etc.), with atmost 6 cameras can be installed. Due to the limitation in the number of cameras available, and based on the investigation conducted beforehand, the positions of the cameras were set at Nos. 2-4 in the tests wherein the bottom boundary was drained. In the case where the bottom was undrained, the cameras were set at location Nos. 1-3.

Next, the model ground was prepared inside the soil container. For this purpose, the necessary amounts of dry soil sample and water were prepared in advance in order to obtain a $60 \mathrm{~cm}$-high model ground with relative density $D_{\mathrm{r}}=80 \%$ and initial degree of saturation, $S_{\mathrm{r}}=30 \%$. The dried soil and water were mixed after which the moist soil was then placed into the soil container in 20 layers, with each layer compacted by a rammer to obtain the prescribed density. In order to provide continuity among the layers, each compacted surface was roughened first before the new layer of sample was placed.

Once the set-up was completed, fully-saturated tensiometers were inserted into the model ground through the side of the container. The insertion positions were set equal to the vertical positions of the cameras. After insertion, water containing dissolved food coloring agent was percolated through the model ground from the top part 
Table 4. Experimental conditions for the vertical seepage test

\begin{tabular}{c|c|c|c|c}
\hline Soil Used & $\begin{array}{c}\text { Initial Saturation } \\
S_{\mathrm{r}}(\%)\end{array}$ & $\begin{array}{c}\text { Dry density } \\
\rho_{\mathrm{d}}\left(\mathrm{g} / \mathrm{cm}^{3}\right)\end{array}$ & Drainage Condition* & $\begin{array}{c}\text { Constant water head } \\
h(\mathrm{~cm})\end{array}$ \\
\hline Toyoura sand & 30 & 1.550 & drained & 2 \\
\hline Toyoura sand & 30 & 1.550 & drained & 5 \\
\hline Toyoura sand & 30 & 1.550 & undrained & 5 \\
\hline Tottori silt & 30 & 1.149 & drained & 5 \\
\hline Tottori silt & 30 & 1.149 & undrained & 5 \\
\hline
\end{tabular}

* condition refers to both air and water

of the container, maintaining a fixed head above the surface of the ground. The drainage conditions (for both air and water) at the bottom boundary of the ground, as well as the fixed water head at the top, were varied. The experimental conditions are listed in Table 4. During infiltration, photo images were taken simultaneously by the cameras, which were connected to a personal computer for controlling the time interval between picture-taking (set at $t=30 \mathrm{sec}$ intervals).

\section{Experimental Results and Discussions}

Figure 10 corresponds to images taken at various prescribed times for the case of Toyoura sand with the lower boundary having drained condition and the water level at the top set at $2 \mathrm{~cm}$. The photo images are $30 \mathrm{~cm}$ high and, as mentioned earlier, correspond to the range from $15 \mathrm{~cm}$ to $45 \mathrm{~cm}$ measured from the bottom of the model ground where the 3 cameras were placed (Nos. 2-4 from the bottom). From the sequence of photos, it is possible to visualize the water as it gradually infiltrates the ground from the top with the passage of time; after 360 $\mathrm{sec}$, the whole ground is colored red in almost uniform fashion. Based on the images taken, the degrees of saturation at various points were calculated from the luminance value, and contour diagrams showing the distributions of $S_{\mathrm{r}}$ at various times were produced, as shown in Fig. 11. Note that the regions in each contour diagram correspond to the square regions shown on the leftmost photo of Fig. 10. The contour diagrams show similar patterns as the photo images, with the $S_{\mathrm{r}}$ increasing significantly in the upper region and changing gradually in the lower part as the infiltration process continued. After $360 \mathrm{sec}$, the whole ground reached almost the same saturation level of $100 \%$. As noted in the figure, the method estimates $S_{\mathrm{r}}$ of fully saturated ground to be in the order of $110 \%$. This indicates that at high saturation levels $\left(S_{\mathrm{r}}\right.$ $\sim 100 \%$ ), the margin of error may be in the order of $\pm 10 \%$, which is still acceptable for practical purposes.

Figure 12 shows the seepage test result for Toyoura sand with the drain valves closed, corresponding to undrained condition at the bottom boundary. The images are also $30 \mathrm{~cm}$ high, but correspond to the range between $5 \mathrm{~cm}$ and $35 \mathrm{~cm}$ from the bottom (with cameras at Nos. 1-3). Comparing with the previous results for drained condition which showed almost one-dimensional seepage from top to bottom, the pattern observed is quite differ- ent, with the entire ground gradually turned red. The corresponding contour diagrams of $S_{\mathrm{r}}$ are shown in Fig. 13 to quantitatively express the results. Unlike the pattern shown in Fig. 11 where the saturation level was initially high in the upper portion followed by the gradual increase in $S_{\mathrm{r}}$ in the lower portion with the passage of time, it seemed that in this case, the whole ground showed almost the same distribution of $S_{\mathrm{r}}$ with the passage of time. Furthermore, it appeared that the degree of saturation was lower at points near the sides of the container. The reason for this was that air, which was present in the voids of initially unsaturated ground, tried to escape as the infiltrating water traveled downward; since the bottom boundary was closed, the trapped air was displaced to the sides and attempted to travel upward. Such a phenomenon was explained by Maruoka et al. (2006) through model tests and numerical simulations considering two-phase flow of air and water in unsaturated soils. Therefore, the $S_{\mathrm{r}}$ within the whole model ground appeared to rise comparatively slowly and evenly because the infiltrating water changed places with the air in the voids.

Next, the experimental results for Tottori silt are described. The infiltration process for drained bottom condition is shown in Fig. 14. There is no remarkable difference when compared to the results of Toyoura sand; however the infiltration rate from the top proceeded at a much gradual rate with the passage of time. Such appearance is expressed quantitatively in terms of the contour diagram of saturation level shown in Fig. 15. In the figure, the expansion of the saturated region from the upper part with the passage of time is very evident.

Similar to Toyoura sand, undrained condition was also conducted on Tottori silt with the lower drain valve shut. The photo images taken at various times are shown in Fig. 16. As in Fig. 14, it was difficult to confirm the changes in the general appearance of the ground made of Tottori silt, although it is apparent that the ground became a little damp. From these images, the degrees of saturation were estimated and the contour diagrams are shown in Fig. 17. Note that the diagrams are remarkably different from the photo images because the changes in $S_{\mathrm{r}}$ with time are more evident this time. Comparing with the results for drained condition, it appears that the patterns are quite similar, except for the increased degree of saturation at the bottom of the undrained case. This observa- 


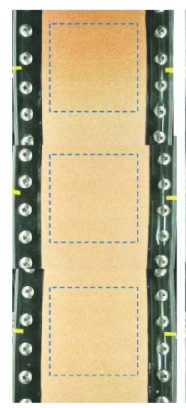

90sec

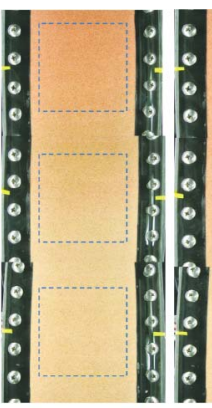

$180 \mathrm{sec}$

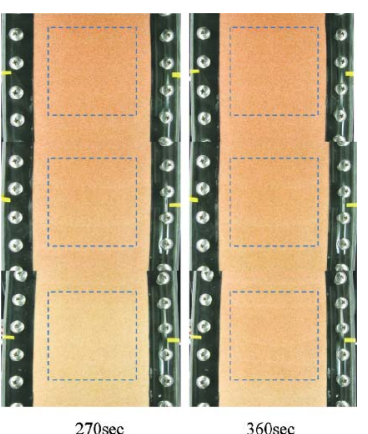

$360 \mathrm{sec}$

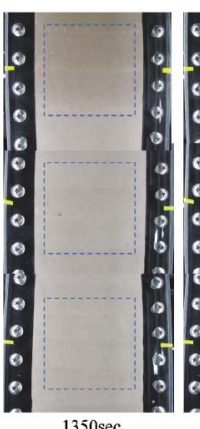

$1350 \mathrm{sec}$

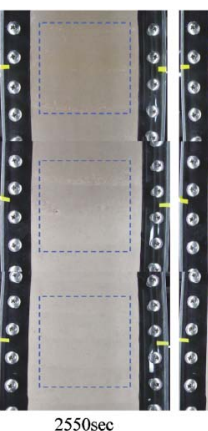

$2550 \mathrm{sec}$

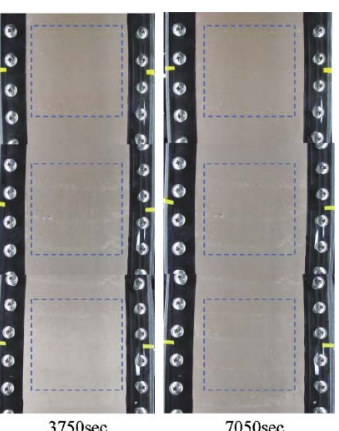

$7050 \mathrm{sec}$
Fig. 10. Photo images from seepage test (Toyoura sand, drained; $h=2$ cm)
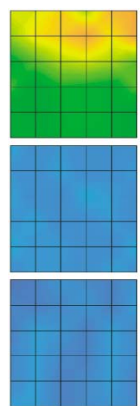

$90 \mathrm{sec}$
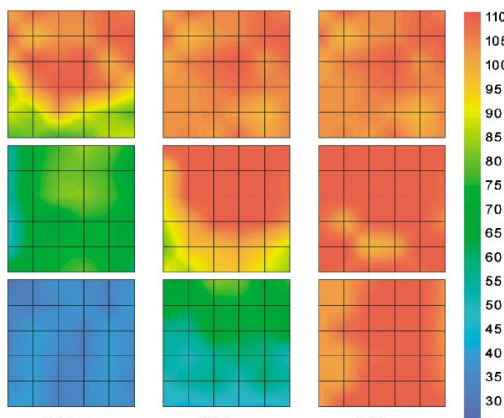

180 sec

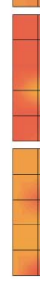

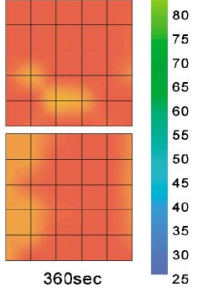

Fig. 11. Contour diagrams of degree of saturation at different periods of time (Toyoura sand, drained; $h=2 \mathrm{~cm}$ ). For each time interval, each square region shown corresponds to the square region indicated by broken lines in Fig. 10

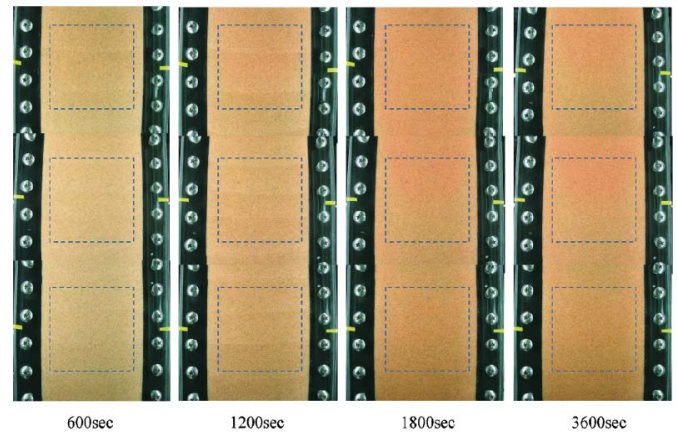

Fig. 12. Photo images from seepage test (Toyoura sand, undrained; $h$ $=5 \mathrm{~cm})$
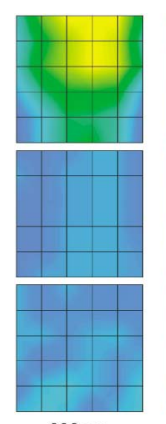

600 sec
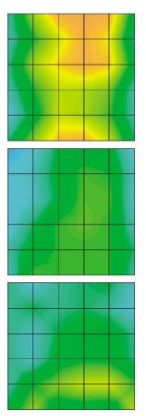

1200 sec
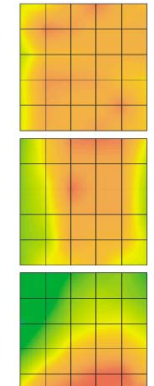

1800 sec

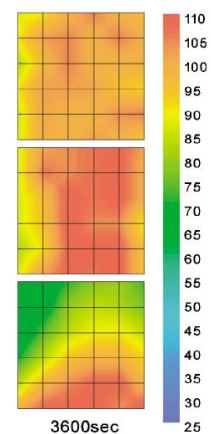

3600

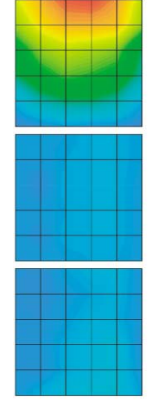

$1350 \mathrm{sec}$
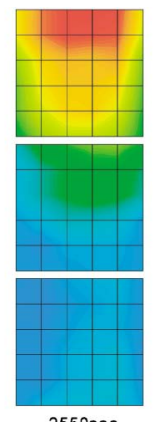

$2550 \mathrm{sec}$
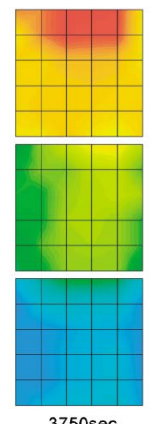

$3750 \mathrm{sec}$

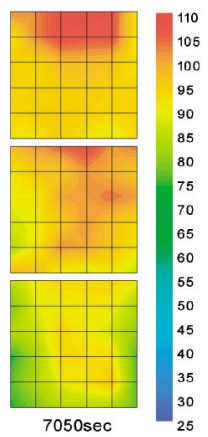

Fig. 15. Contour diagrams of degree of saturation at different periods of time (Tottori silt, drained; $h=5 \mathrm{~cm}$ ). For each time interval, each square region shown corresponds to the square region indicated by broken lines in Fig. 14

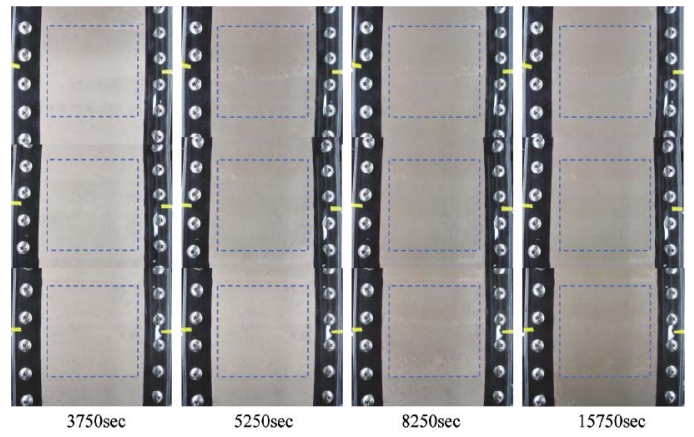

Fig. 16. Photo images from seepage test (Tottori silt, undrained; $h=5$ cm)
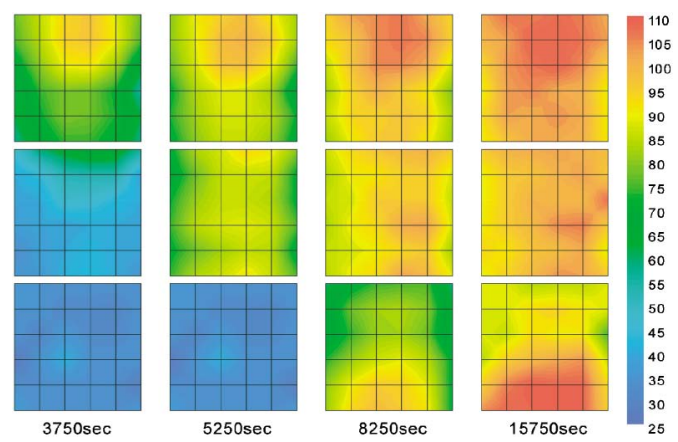

Fig. 17. Contour diagrams of degree of saturation at different periods of time (Tottori silt, undrained; $h=5 \mathrm{~cm}$ ). For each time interval, each square region shown corresponds to the square region indicated by broken lines in Fig. 16 of time (Toyoura sand, undrained; $h=5 \mathrm{~cm}$ ). For each time interval, each square region shown corresponds to the square region indicated by broken lines in Fig. 12 
tion indicates that whether drained or undrained, Tottori silt shows practically similar seepage response. This is because the coefficient of permeability of Tottori silt is so low that the seepage velocity is not much affected by the drainage condition. The infiltration of water takes place by gradually changing places with air in the voids.

Finally, the relations between the degree of saturation obtained by tensiometer and those computed from the processed images at the same location are shown in Fig. 18 for Toyoura sand. Note that although the intent is to compare the values at the same location, it is known that a tensiometer measures $S_{\mathrm{r}}$ at a "point", while image analysis averages the $S_{\mathrm{r}}$ within an "area'. However, because the tensiometer has a diameter of about $6 \mathrm{~mm}$ while the area analyzed digitally is $1 \mathrm{~cm} \times 1 \mathrm{~cm}$ (or 200 pixel $\times 200$ pixel), the two regions (which are much smaller than the width of the container) can be considered similar for practical purposes. Figure 18(a) is for drained lower boundary and it can be seen that there is a good agreement between the $S_{\mathrm{r}}$ measured by tensiometers and by image processing, showing the validity of the proposed method. On the other hand, the results for the undrained conditions depicted in Fig. 18(b) show poor correlation, with the tensiometers indicating higher values of $S_{\mathrm{r}}$ at the initial stage of the test. This is because the increase in pressure due to the trapped air in the ground influenced the pore water pressure monitored by the tensiometer.
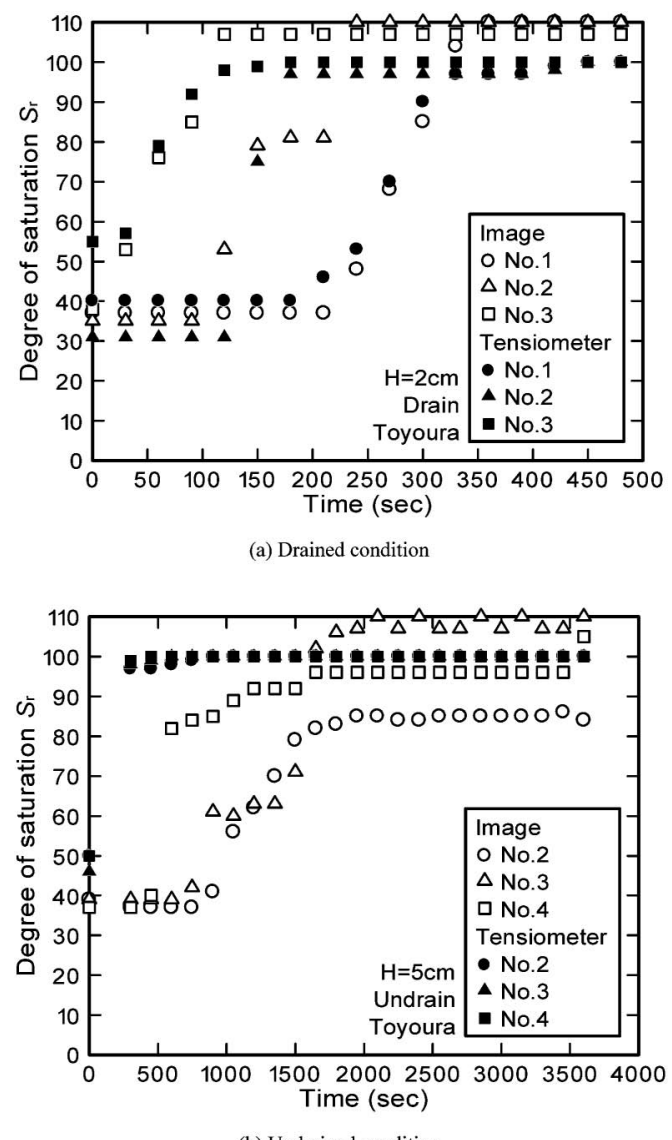

Fig. 18. Time histories of degree of saturation for Toyoura sand: (a) drained condition; (b) undrained condition
Similar observation was made by Nishigaki et al. (2007) in their field tests using conventional tensiometers.

The corresponding results for Tottori silt are shown in Fig. 19. As previously mentioned, the results for Tottori silt were generally not affected by the drainage condition at the lower boundary, and showed good agreement between the saturation levels monitored by both methods.

The degrees of saturation obtained from image analysis and those from tensiometers are compared in Figs. 20(a) and (b) for Toyoura sand and Tottori silt, respectively. It can be observed that there is almost one-to-one correspondence between the two methods for Tottori silt under both drained and undrained conditions. Also the quick response of the tensiometer was very evident in the undrained case of Toyoura sand.

Therefore, the seepage experiment results discussed above confirmed the validity of the proposed method of measuring the degree of saturation of the whole ground by digital image processing. As an application, it was able to examine in detail the difference in seepage characteristics between Toyoura sand and Tottori silt. It is recommended therefore that similar tests be performed in the future on soils with different grain sizes, such as clays and gravels.

It is worthy to mention that although the calibration was performed on samples with $S_{\mathrm{r}}<60 \%$, good agreement with the results from seepage tests were obtained
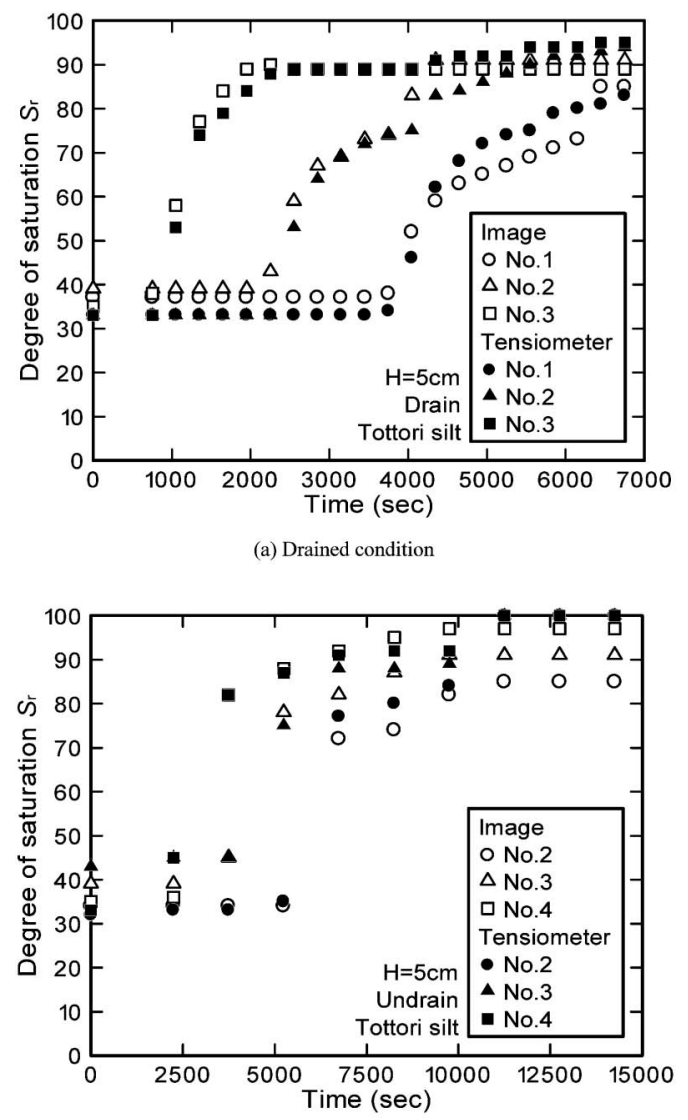

(b) Undrained condition

Fig. 19. Time histories of degree of saturation for Tottori silt: (a) drained condition; (b) undrained condition 


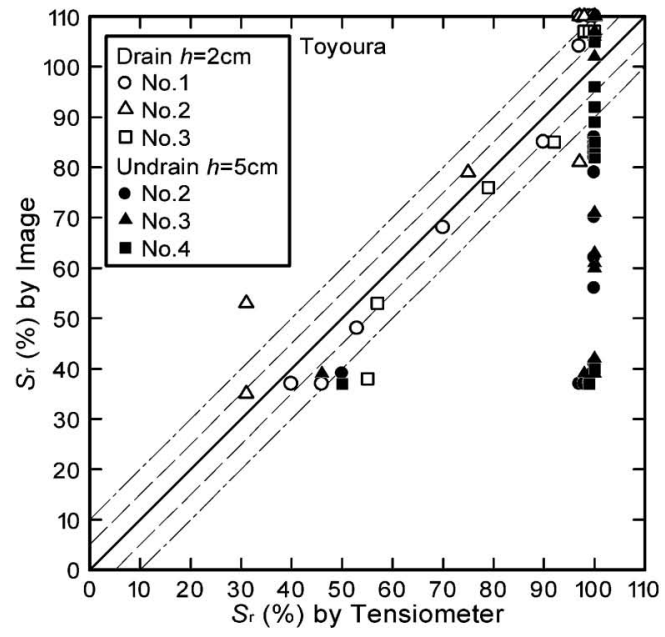

(a) Toyoura sand

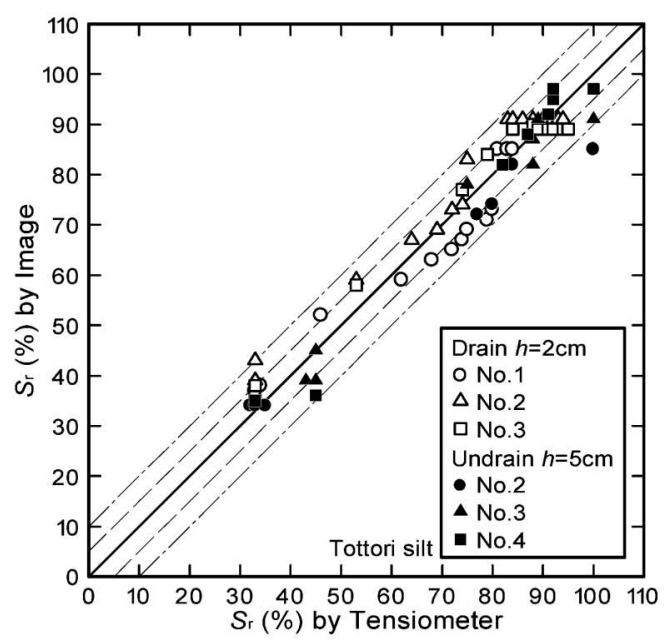

(b) Tottori silt

Fig. 20. Comparison of degrees of saturation obtained by image analysis and by tensiometer: (a) Toyoura sand; (b) Tottori silt

when the calibration data were extrapolated to higher values of $S_{\mathrm{r}}(>60 \%)$ using the calibration curves. To further increase the accuracy of prediction, it is also recommended that additional data points, particularly those corresponding to higher $S_{\mathrm{r}}$, be obtained during the calibration stage to cover the whole possible range of degree of saturation.

The proposed method has wide applicability, ranging from laboratory experiments to physical modeling and in-situ determination of degree of saturation. For field application, digital cameras can be lowered on pre-drilled boreholes and photo images can be taken and analyzed to estimate the degree of saturation of a fairly large region of the ground. Although the application may be limited to only plane-strain seepage conditions, the method represents a viable alternative to conventional procedures of determining the saturation ratio of soils.

\section{CONCLUSIONS}

In this research, a series of experiments was conducted for the purpose of developing a method to measure the degree of saturation of ground by digital image processing. Based on the results, the following conclusions can be made.

1. The results of the experiments showed that a method to measure the degree of saturation of ground by image processing was possible. From the data presented herein, the relation between degree of saturation and luminance value can be expressed in terms of second degree function.

2. Good correlation between $S_{\mathrm{r}}$ and luminance value was obtained separately for two soil samples with different colors and grain size distributions. The margin of error was in the order of $\pm 5 \%$.

3. The method illustrates the possibility of measuring the degree of saturation of a larger portion of the ground, which is difficult to perform using conventional procedures. With this method, contour diagrams of degree of saturation can be produced, making it possible to visualize the propagation of the saturated region. Moreover, it was able to examine the movement of water, and possibly of air, under drained/undrained condition.

4. For drained condition, the proposed method showed good agreement with the results obtained by conventional tensiometers. For undrained condition, however, the proposed method seems to be better because the trapped air appeared to influence the readings obtained by tensiometers.

5. The proposed method is highly affected by the quantity of lighting the ground is subjected to. Hence, it is important to take care that all the conditions are maintained throughout the duration of the measurement.

\section{REFERENCES}

1) Bruce, R. R. and Klute, A. (1956): The measurement of soil moisture diffusivity, Soil Sci. Soc. Amer. Proc., 20, 458-462.

2) Darnault, C. J. G., Throop, J. A., DiCarlo, D. A., Rimmer, A., Steenhuis, T. S. and Parlange, J. Y. (1998): Visualization by light transmission of oil and water contents in transient two-phase flow fields, Journal of Contaminant Hydrology, 31(3-4), 337-348.

3) Falleiros, M. C., Ravelo Sanchez, A., Dornelas de Souza, M., Bacchi, O. O. S., Pilotto, J. E. and Reichardt, K. (1993): Neutron probe measurement of soil water content close to soil surface, Scientia Agricola, Piracicaba, 50(3), 333-337.

4) Fredlund, D. G. and Rahardjo, H. (1993): Soil Mechanics for Unsaturated Soils, John Wiley \& Sons. Inc.

5) Gurr, C. G. (1962): Use of gamma-rays in measuring water content and permeability in unsaturated columns of soil, Soil Sci. Soc. Amer. Proc., 94, 224-229.

6) Japanese Geotechnical Society (2004): Behavior of Unsaturated Soils and Its Evaluation, Hokosya Press, 223 (in Japanese).

7) Kechavarzi, C., Soga, K. and Wiart, P. (2000): Multispectral image analysis method to determine dynamic fluid saturation distribution in two-dimensional three-fluid phase flow laboratory experiments, Journal of Contaminant Hydrology, 46(3-4), 265-293.

8) Lukangu, G., Savage, M. J. and Johnston, M. A. (1999): Use of sub-hourly soil water content measured with frequency-domain reflectometer to schedule irrigation of cabbages, Irrigation Science, 19, 7-13.

9) Luthin, J. N. and Miller, R. D. (1953): Pressure distribution in soil 
columns draining into the atmosphere, Soil Sci. Soc. Amer. Proc., 17, 329-333.

10) Maruoka, Y., Yoshimoto, N., Nakata, Y., Hyodo, M. and Arii, T. (2006): Two-phase flow of air and water in unsaturated ground, Ground Engineering, 24(1), 69-79 (in Japanese).

11) Nakajima, M., Inoue, M., Sawada, K. and Nicholl, C. (1998): Measurement of soil water content by Amplitude Domain Reflectometry method and its calibration, Journal of Groundwater Hydrol$o g y$, 40(4), 509-519 (in Japanese).

12) Nishigaki, M., Komatsu, M. and Shirashi, T. (2007): Research on the measurement method of the rainwater infiltration behavior considering the influence of pore air during rainfall, Proc. 59th Annual Conference of the Japan Society of Civil Engineers Chugoku Branch, Ube, 207-208 (in Japanese).

13) Nissen, H. H., Moldrup, P. and Henriksen, K. (1998): High-resolution time domain reflectometry coil probe for measuring soil water content, Soil Sci. Soc. Am. J., 62, 1203-1211.

14) Schincariol, R. A. and Schwartz, F. W. (1990): An experimental investigation of variable density flow and mixing in homogeneous and heterogeneous media, Water Resources Research, 26(10), 2317-2329.

15) Topp, G. C., Davis, J. L. and Annan, A. P. (1990): Electomagnetic determination of soil water content: measurements in coaxial transmission lines, Water Resources Research, 16(3), 574-582.

16) Umeda, Y. (1969): On the measurement of soil moisture, Journal of the Japanese Society of Irrigation, Drainage and Rural Engineering, 37(8), 550-551 (in Japanese).

17) Uno, H. (1970): Research on unsteady seepage in soil and groundwater level fluctuation, $B E$ Thesis, Kyoto University (in Japanese).

18) Urano, Y., Komine, H., Yasuhara, K. and Murakami, S. (2006): A proposal of new color measuring method using a digital camera and a color evaluation index for building stones, Journal of Geotechnical Engineering, 62(4), 793-802 (in Japanese).

19) Visualization Society of Japan (2002): PIV Handbook, Morikita Shuppan Co., Ltd., 82-85 (in Japanese).

20) White, D. J., Take, W. A. and Bolton, M. D. (2003): Soil deformation measurement using particle image velocimetry (PIV) and photogrammetry, Géotechnique, 53(7), 619-631. 